\title{
OLFACTORY GROOVE MENINGIOMA: DOES ANOSMIA IMPROVE FOLLOWING SURGERY? REPORT OF 20 SURGICALLY TREATED PATIENTS IN DHAKA MEDICAL COLLEGE HOSPITAL, DHAKA
}

\author{
DAS $\mathrm{S}^{1}$, ISLAM MM ${ }^{2}$, RAHMAN MM ${ }^{3}$, RAHMAN MZ ${ }^{4}$, ISLAM MR ${ }^{5}$, SUBHAN KI ${ }^{6}$
}

\begin{abstract}
:
Objective: Olfactory Groove Meningioma(OGM) are rare benign tumour account for $8-13 \%$ of all intracranial meningiomas and reported about $12 \%$ of all basal meningiomas. Anosmia is thought to be among the commonest symptoms, even though patients often present with headache, visual problem and mental dysfunction.
\end{abstract}

Methods: Tweenty patients (male $=12$ andfemale $=8$ ) with olfactory groove meningioma were examined. In all patients extensive pre operative and post operative olfactory testing was performed using conventional soap and cotton soaked with perfume. In 14 cases, meningioma was lateralized (8 -Left, 6 -Right), in 6 patients meningioma were extended in both sides. CT and MRI scans were performed in all cases.

Results:In preoperative testing, 14 patients were found to be anosmic on the side of the tumor, 2 were hyposmic and 4 were normosmic. Postoperative ipsilaterally all patients became anosmic but contralaterally 14 patients were anosmic ,2 were hyposmic and 4 were normosmic.

Conclusion:The likelihood of normal post operative olfactory function preservation contra lateral to the tumour was possible in too some extent in smaller size.However,preservation of olfactory function ipsilateral to the tumor seems to be extremely difficult irrespective of tumor size or surgical approach.

Keywords: Olfactory groove meningioma(OGM), Anosmia, Bifrontal craniotomy.

J Dhaka Med Coll. 2015; 24(1) : 44-46.

\section{Introduction:}

OGM are rare benign intracranial tumors account for $8-13 \%$ of all intracranial meningioma, represent about $12 \%$ of all basal meningiomas. In histological series, they represent $8-18 \%$ of all intracranial meningioma. ${ }^{1-3}$ Meningioma originate from arachnoid cap cells which are specialized cells in arachnoid granulations. ${ }^{4,5}$ They are slowly growing tumors and usually remain clinically undetectable during the early stages. ${ }^{6}$
Therefore they are often considerable size when present to the Neurosurgeon. ${ }^{7-8}$ Unilateral or bilateral olfactory dysfunction is supposed to be the earliest symptoms only a few patients are aware of olfactory loss. Most patients present with headache and visual disturbances, mental and intellectual functions or memory disturbance. ${ }^{8,9}$ However investigation of olfactory function in a large group of patients are lacking so far. But in present series of 20 cases with olfactory groove

1. Dr. Sukriti Das, Associate Professor, Department of Neurosurgery, Dhaka Medical College \& Hospital, Dhaka.

2. Dr. Md.Manirul Islam, Indoor Medical Officer, Department of neurosurgery, Dhaka Medical College Hospital, Dhaka.

3. Dr. Md. Mahfuzur Rahman, Assistant register, Department of Neurosurgery, Dhaka Medical College Hospital, Dhaka.

4. Professor Dr. Md. Zillur Rahman, Professor and Head, Department of Neurosurgery, Dhaka Medical College \& Hospital, Dhaka.

5. Dr. Md. Rafiqul Islam, Assistant Professor, Department of Neurosurgery, Dhaka Medical College \& Hospital, Dhaka.

6. Dr. Kazi Irfan Subhan, MS Resident, Department of Neurosurgery, Dhaka Medical College Hospital, Dhaka. Correspondence: Dr. Sukriti Das, Associate Professor, Department of neurosurgery, Dhaka Medical College Hospital, Dhaka. Cell Phone:+8801711676848, Email: sukriti66@yahoo.com. 
meningioma who underwent surgery, we tried to analyzepost operative surgical outcome.

\section{Methods:}

We examined 20 patients among them 12 men and 8 women, with a mean age of 43 years (range 20-62 years) who presented to DhakaMedical College Hospital, Dhaka, between 2009 and 2014. Tumor diagnosis was performed in all patients by post contrast CT scan and MRI scan of brain. All patients were operated by bifrontal craniotomy in the Neurosurgery department of Dhaka Medical College Hospital, Dhaka.

\section{Results:}

The tumor was localized on the left side in 8 , on the right side in 6 and bilateral in rest 6 patients. Tumor size ranged from 2 to $5.5 \mathrm{~cm}$ in diameter.

Removal ofmeningiomas were achieved according to impson grade II \& III in all cases. 14 patients had unilateral tumors and 6 had bilateral tumors.

According to olfactory function testing and neuro image findings, preoperatively 4 patients were found to be normosmic on both sides, 2 patients were hyposmic on both sidesand 14 patients had anosmia on ipsilateral side of the tumor.

Contra lateral pre op and post op olfactory function
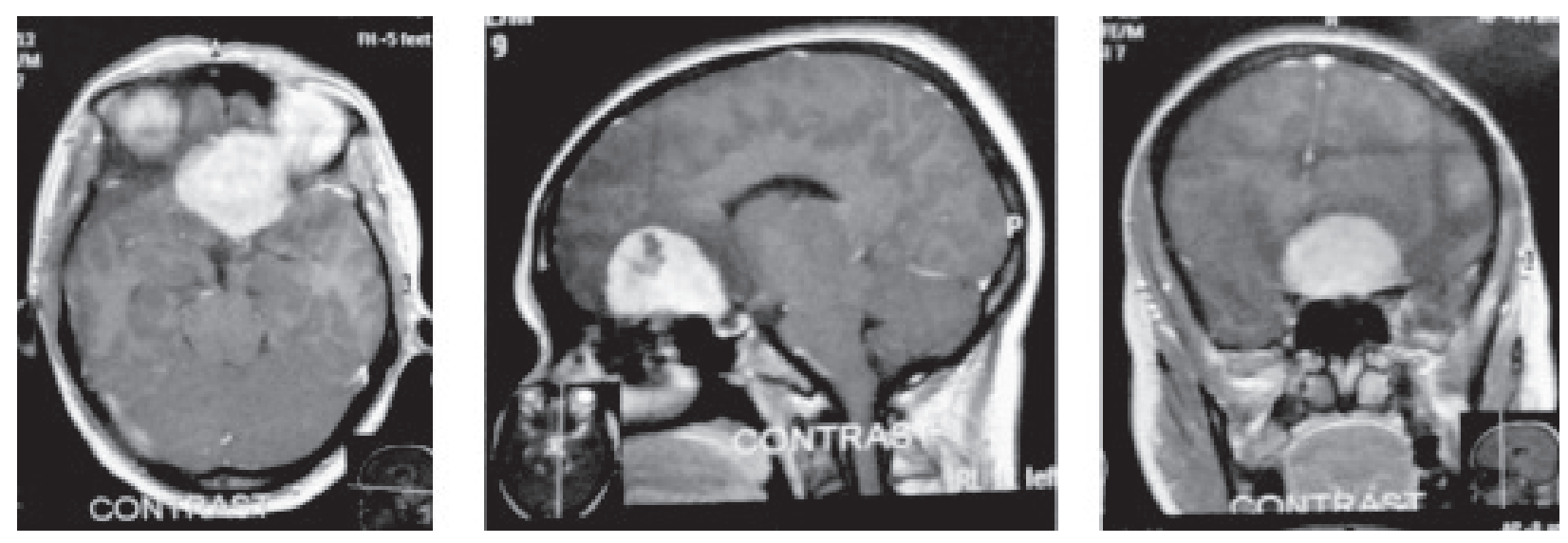

Fig.-1 : Preoperative postcontrast axial, sagital and coronal MRI scan of Olfactory Groove Meningioma.

\section{Ipsilateral pre op and post op olfactory function}

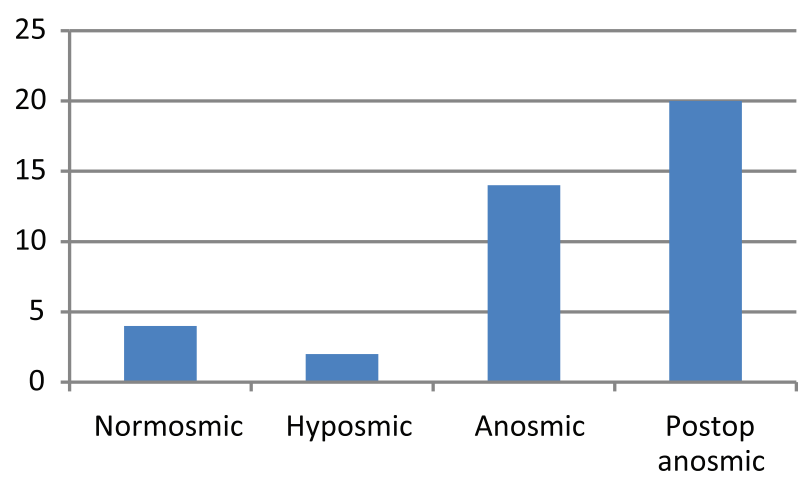

n Ipsilateral pre op and post op olfactory function

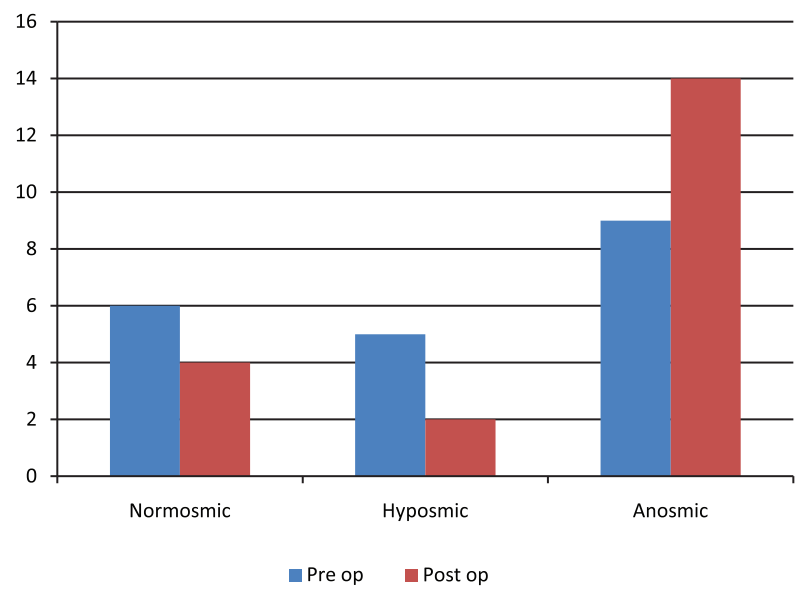

Fig.-3

Fig.-2 


\section{Discussion:}

About $8-13 \%$ of all intracranial meningiomas are olfactory groove meningiomas ${ }^{1}$. Meningiomas are originated from arachnoid cap cells, which are specialized cells in the arachnoid granulation. They are slow growing tumours that usually remain undetectable during the early stages and reach a very large size of $>4 \mathrm{~cm}$ at before the diagnosis is made ${ }^{10}$. Although anosmia is thought to be an early symptom but surprisingly only a few patients complain of olfactory dysfunction $(60 \%)$. This may be due the gradual decline in olfactory function as it is maintained by the contralateral side $^{11}$. Thus lateralized anosmia is extremely difficult to detect during routine clinical examination in patients in whom It is the only neurological symptom before the tumour become large enough to affect other structures. In our series we had four patients who were bilaterally normosmic and on the remaining patients either anosmic or hyposmic.

Size of OGM seems to be a major factor in post operative olfactory function preservation in contralateral side. Ipsilateral preservation of olfactory function is very difficult irrespective of size of tumour, duration of surgery and surgical approaches.

On the side contralateral to the tumour, preservation of the olfactory function was possible in 6 patients in whom the tumour was less than $3 \mathrm{~cm}$ In diameter and preoperative normosmia had been established on both sides.

\section{References:}

1. McDermott MW, Wilson CB.Meningiomas in neurological surgery. Youmans JR. ed. 4th ed. Philadelphia: Saunders; 1996.

2. Chan RC, Thompson GB. Morbidity, mortality and quality of life following surgery for intracranial meningiomas :a retrospective study of 257 cases. J Neurosurg1994; 60:52-60.

3. Cushing $\mathrm{H}$ Eisenhart L. Meningiomas : their classification, regional behavior, life history, and surgical end results. 1938.

4. Kepes JJ. Meningiomas :biology, pathology and differential diagnosis. New York: Masson; 1982.

5. O'rahilyR, Miler F. The meninges in human development. J Neuro phthalmological Exp Neurol 1986; 45: 588-608.

6. RachilinJR, RosenbalmML. Etiology and biology of meningiomas. In: meningiomas. Al-mefty.ed. New York: Raven;1991.

7. Babu R, Barton A, KasoffSS(1995) Resection of olfactory groove meningiomas :technical note revisited. SurgNeurol1995; 44: 567-72.

8. Bakay L. Olfactory meningiomas. The missed diagnosis.JAMA 1984; 251: 53-5.

9. Tsikoudas A, Martin-Hirsch DP(1999) Olfactory groove meningiomas. ClinOltolaryngol 1999; 24: 507-9.

10. Schmitt HE, Ahyai A, Spoerri O. Die Verantwortung des HNO-ArztesbeiErkennung des Olfaktoriusmeningioms HNO 1982; 30: 56-9.

11. Klimek L, Hummel T, Moll B, et al.Lateralized and bilateral olfactory function in patients with chronic sinusitis compared to healthy controls. Laryngoscope 1998; 108:111-4. 